\title{
Creative University: A Definition and Activities Management Based on the Completion of Key Performance Indicator (KPI)
}

\author{
Sutanto Sutanto ${ }^{1 \star}$, Alexander Yonathan Christy ${ }^{1}$ Dianisa Khoirum Sandi ${ }^{2}$
}

\begin{abstract}
The study's objectives are to make a definition of Creative University and describe the activities management towards creative university based on the Key Performance Indicator (KPI) completion. Universities have KPI which consists of Index of Activities Performance (IAP) and Index of Main Performance (IMP) with the constraints of time and cost. Creative University is a university with creative activities such that the completion of KPI is accomplished within shorter duration and less cost. There are three activities management to accelerate the KPI completion those are creating activities that could minimize the distance between IAP and IMP, creating the schedule of activities, and managing the schedule based on the strategy of academic phases in university.
\end{abstract}

Keywords: Creative University; Key Performance Indicator (KPI); Indicator of Activities Performance (IMP); Indicator of Activities Performance (IAP); Management of activities

Summary: Creativity and innovation are very crucial elements required by all life sectors to compete in the current era of globalization. Being labelled as 'creative' is positive and attractive for an organization in a competitive world. Key Performance Indicator (KPI) is measurable value demonstrating how effectively an organization is achieving their objectives. KPI consists of output, known as Indicator of Activities Performance (IAP) and outcome or Indicator of Main Performance (IMP). Universities have quantifiable IMPs and IAPs. There are cost and time constraints in realizing IAPs and IMPs to complete the KPI. The term of 'Creative University' has never been reviewed on any reports. The study's objectives are to make a definition of Creative University based on the KPI completion and to describe the management of activities to accelerate the KPI completion towards creative university. The observation data were KPI of activities synchronized by the Quadqurelli Symonds (QS) system and activities managed by one of national universities in Indonesia. In this study, a number of graphs were made as illustrations to answer the objectives. The variables of the graphs were the observation data and the constrains of cost and time. Several of the graphs implemented several basic concepts of mathematics and physics including the first-degree polynomial function, Density Theorem of real number, and free parabolic motion. As the result, Creative University could be defined as a university with creative activities such that the completion of KPI is accomplished with shorter duration and less budget. Further, there are three ways to accelerate the completion of KPI towards creative university, those are creating activities such that minimizing the distance between IAP and IMP, making the schedule of activities, and managing the schedule based on the strategy of academic phases in university.

Submitted: August $31^{\text {st }}, 2021 /$ Approved: October $26^{\text {th }}, 2021$

\section{Introduction}

Creativity and innovation are very crucial elements required by all sectors to compete in the current era of globalization. Creativity is the ability to generate new, unique, and useful ideas or products while innovation is the implementation of creativity (Louca et al., 2014). The researches on the term or concept of 'creative' labeled on individuals, regions, organizations, and any economic/ social/ cultural sectors has been abundantly conducted in recent decades. Through the researches, the definitions of creative individuals, creative economy, creative cultures, creative cities, creative industry, creative organizations, etc. have emerged based on its used indicators (Martini, 2016).

Universities or colleges are formal organizations that have a crucial part in a country and its people. University is a place where education and research occur. It also has a contribution to the development of the economic and social fields by training people with high skill, broad knowledge, and enriched culture.
The Creative University is an answer to the demands for conceptualizing, lecturing, and endorsing education and research within the university in new ways (Lund \& Arndt, 2018). Therefore, creative innovations at the individual, collective, organizational, and institutional levels are very much needed. Being labeled as 'creative' is a positive and attractive branding in a competitive world of universities. A University that cannot meet the task of being creative and innovative has a risk to be failed, then being labeled as unattractive and undesirable. Processes of creativity, innovation, and chance are critical to universities. These are essential to improve the quality of a university. A successful university is presumably dependent on its ability to nurture creativity and manage changes at all levels and over time (Lund \& Arndt, 2018).

Key Performance Indicators (KPI) is a quantifiable measure used to evaluate, gauge, and monitor the success level of an organization or its particular activity over time (AlRababah et al, 2017; Badawy et al, 2016; Villazón et al, 2020). It is an indicator or a reference of an

(1) Department of Mathematics, Faculty of Mathematics and Natural Sciences, Universitas Sebelas Maret, Indonesia

(2) Department of Physics, Faculty of Mathematics and Natural Sciences, Universitas Sebelas Maret, Indonesia

${ }^{\star}$ Corresponding author: sutanto71@staff.uns.ac.id 
organization or an activity in meeting their goals (Sawang, 2011). The KPI of an organization is different depending on the type of the organization. A university or college might deliberate the five-year graduation rate as the KPI, while an academic library might use a collection availability rate as the KPI (Badaway et al, 2016; Peter, 2014).

KPIs are general indicators of performance that focus on important components those are outputs and outcomes. Output refers to a direct result of innovative efforts of the organization manager and outcomes are the consequences of the introduction of innovations (Janger et al, 2017; Aurora \& Kaur, 2015). In Indonesia, the output and outcome of KPI are respectively known as Indicators of Activities Performance (IAP) and or Indicators of Main Performance (IMP). Both outputs and outcomes are quantitatively measurable (Janger et al, 2017; Europian Commission, 2013).

To the best of our knowledge, studies related to the terms and indicators of Creative University have never been reported. The existing studies generally discussed creative students (Ritter et al, 2020), investigations and assessments of student creativity level using certain methods (Brockunier, 2016), creative learning methods (Suyidno et al, 2019), creative learning environment, and other related matters (Hu \& Adey, 2002; Prayudi et al, 2017). Additionally, KPI has been employed mostly for various assessments associated with the performance of organizations, enterprises, or institutions (Villazón et al, 2020; Sawang, 2011; Peter, 2014; Aurora \& Kaur, 2015; Selviyanti et al, 2021), however, the utilization of KPI as an indicator to determine 'Creative University' and deliberate 'what should be done towards a creative university' has never been reported. Therefore, the objectives of this study are to make a definition of Creative University and discuss activities managements towards a creative university based on the KPI completion.

\section{Method}

The observation data of this study were KPI, IMPs, and IAPs of activities synchronized by the indicator from Quadquarelli Symonds/ QS ranking system and the activities data managed by one of national universities in Indonesia. There were two constraints in realizing IAPs and IMPs to achieve KPI. The constraints were cost and time.

In this study, in order to answer the objectives, a number of graphs were made to give illustrations. The variables of the graphs were the observation data and the constrains of cost and time. Several of the graphs implemented several basic concepts of mathematics and physics including the first-degree polynomial function (Eq. 1), Density Theorem of real number, and free parabolic motion (Eq. 3). Based on the illustration graphs, the definition of Creative University and the activities management with the constraints of cost and time could be described.

\section{Results and Discussion}

Definition of Creative University based on the completion of KPI. Universities in Indonesia possess KPIs which are derived into IMPs. IMP is then derived into IPAs. For example, the KPI of "creating the professional faculties" is derived into IMPs of " $80 \%$ of Faculties with $\mathrm{PhD}$ " (synchronized by the indicator from Quadquarelli Symond/ QS ranking system). Activities like holding a workshop of scholarship, creating a research group supervised by a professor of an international university, pronouncing the regulation of international scholarship, etc. are managed. IAPs are the quantitative output of these activities so that the IMP would be attained and the KPI is completed. The KPIs must contain a positive impact on academic study, research, and society (Secundo et al, 2017).

The progression of IMPs is monitored in a series of times. The data of the IMP progress to the time are used to estimate the duration in completing the KPI of a university. The achievement of KPIs in universities is restricted by time. In reality, there are universities that could complete the KPIs on time or before the allotted time, even there are also universities completing the KPIs after the allotted time or failed. The universities that finish the KPIs before the allotted time reveal that they can complete KPIs in less duration. Thus, from this description, the illustration graph can be seen in Figure 1.

In Figure 1, there are $n+1$ paired data of time and KPI completion percentage denoted as $\left(t_{i}, f\left(t_{i}\right)\right), i=0,1, \ldots, n$. The data of $\left(t_{0}, f\left(t_{0}\right)\right)$ and $\left(t_{n}, f\left(t_{n}\right)\right)$ represent the initial condition and the current condition according to the KPI completion respectively. First, we made the completion plot as the horizontally straight line denoted by a function $f(t)=100 \%$.

Figure 1: The graphical representation of KPI completion by approximation curve. The time is calculated in the year and the completion is calculated in percent. The "creative curve" (green) would complete the KPI with a shorter duration than the expected duration from the "normal curve:" (Red).

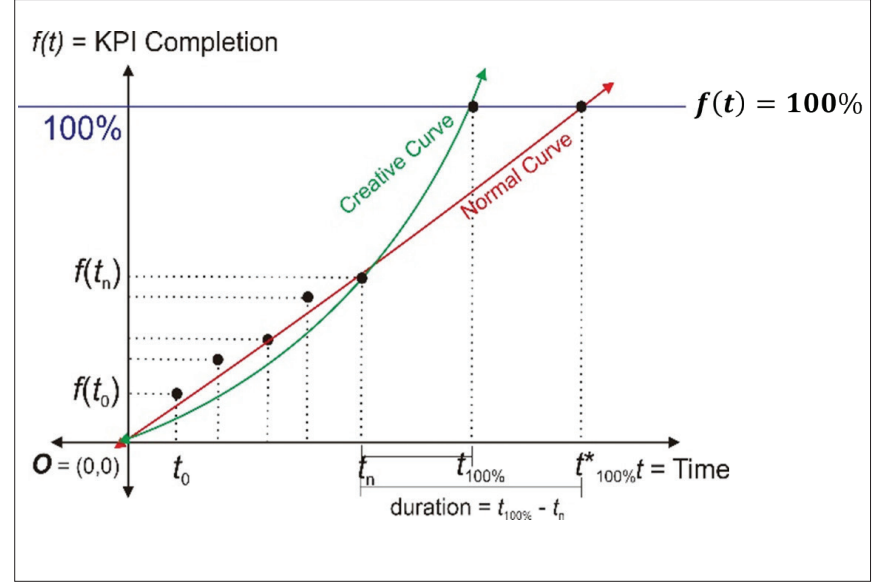

The paired data are used to find the first-degree polynomial as an approximation plot. This plot is called the "normal curve" and is demonstrated as the red curve in Figure 1. The normal curve and the completion plot form an intersection at a point of, $\left(t_{100 \%}^{*}, 100 \%\right)$, where $t_{100 \%}^{*}>t_{n}$. Thus, we refer that the estimated duration in completing the KPI is $t_{100 \%}^{*}-t_{n}$.

By the Density Theorem of real number (Bartle \& Sherbert, 2011), if if $t_{100 \%}^{*}>t_{n}$ and both of $t_{100 \%}^{*}$ and $t_{n}$ are real numbers. then there must be a real number $t_{100 \%}$ such that $t_{n}<t_{100 \%}<t_{100 \%}^{*}$. Hence, we can create an alternative curve called "creative curve" as the green curve in Figure 1. This curve has an intersection with the completion 
plot at a point of $\left(t_{100 \%}, 100 \%\right)$, where $t_{n}<t_{100 \%}<t_{100 \%}^{*}$. So now, the estimated duration in completing KPI becomes $t_{100 \%}-t_{n}$. This means that the KPI could be completed in less duration. This result is in line with the Parkinson's Law (Parkinson, 1957; Parkinson, 1958) that the goal actually could be achieved faster than its estimated duration.

Figure 2: Graphical image to explain the correlation between acceleration and the gradient increment of the approximation curve. The illustration displays that the gradient of the is directly proportional to acceleration.

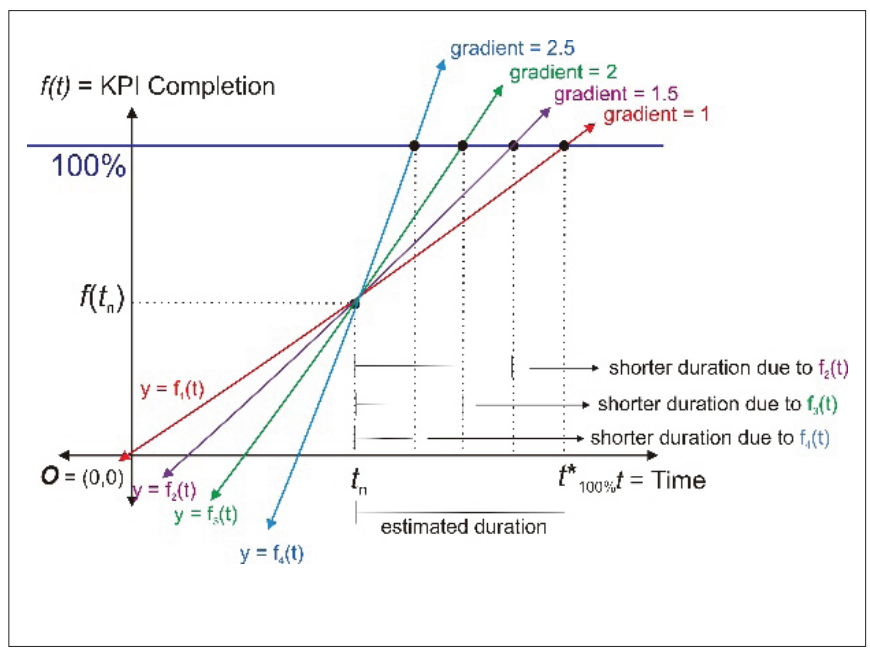

The reduction of the duration in completing the KPI from $t_{100 \%}^{*}-t_{n}$ to $t_{100 \%}-t_{n}$ (Figure 1) is called acceleration. This indicates that universities experience accelerated performances or progressions to achieve KPI. To ease the understanding, the calculation is then simplified. We made several approximation plots by using the first-degree polynomial function as shown in Figure 2. In Figure 2 , it is apparent that the acceleration occurs by increasing the gradient of the approximating curves. Reducing the completion function below $100 \%$ is not an available option.
The "normal curves" in Figure 1 represent the university that produces the progressions slowly with focusing on the annual repetitions. The University with this management is included in the traditional style because it relies too much on the traditions and difficult to create innovations (Sen et al, 2012). The "creative curves" exhibit the university that makes the progression faster than the estimated duration of KPI completion.

Universities that experience acceleration in completing KPIs must use their creativities to generate creative and innovative systems/ programs/ activities and manage them properly so that the KPIs can be completed in less duration. Therefore, from this study, we define a "Creative University" as a university with activities such that the completion of KPI is reached within less duration than its estimated duration. The next question is how to accelerate the progression of KPI completion? Hence, the next section will discuss this matter.

Management of activities to accelerate the completion of the KPI completion. Let the approximation curve of the $f(t)$ be as Eqs. 1 .

$$
f(t)=m t+c
$$

The function $f(t)$ exhibits the KPI completion to the time year, thus $f(t+1) \geq f(t)$. The constant $m \geq 0$ is the gradient of the curve and $c$ in the set of real numbers $(\mathbb{R})$. That means the average progression is m\%/year.

For every $t \in \mathbb{R}, t>0$, if $f(t+1)-f(t)=0$, then the average of the progression is $m \% /$ year, or no progress at all. In this case, the university will never complete the KPI. If $f(t+1)-f(t)=m$, then the average of the progression is $m \% / y e a r$, thus the university will complete the KPI exactly at the estimated duration. Acceleration occurs if $f(t+1)-f(t)>m$ or $f(t+1)-m>f(t)$ for every $t \in \mathbb{R}$.

The difference between the progress every year and the average progress $(m)$ is simply compared by rotating (clockwise) the "normal curve" in Figure 1 by $45^{\circ}$. Such that the approximation curve is parallel to the $\mathrm{X}$-axis, and the Y-Axis is transformed into the axis that denotes the value of $f(t+1)-m$. This transformation is demonstrated in Figure 3 .

Figure 3: Transformed form of completion of KPI to compare the difference between progression () and the average progression ().

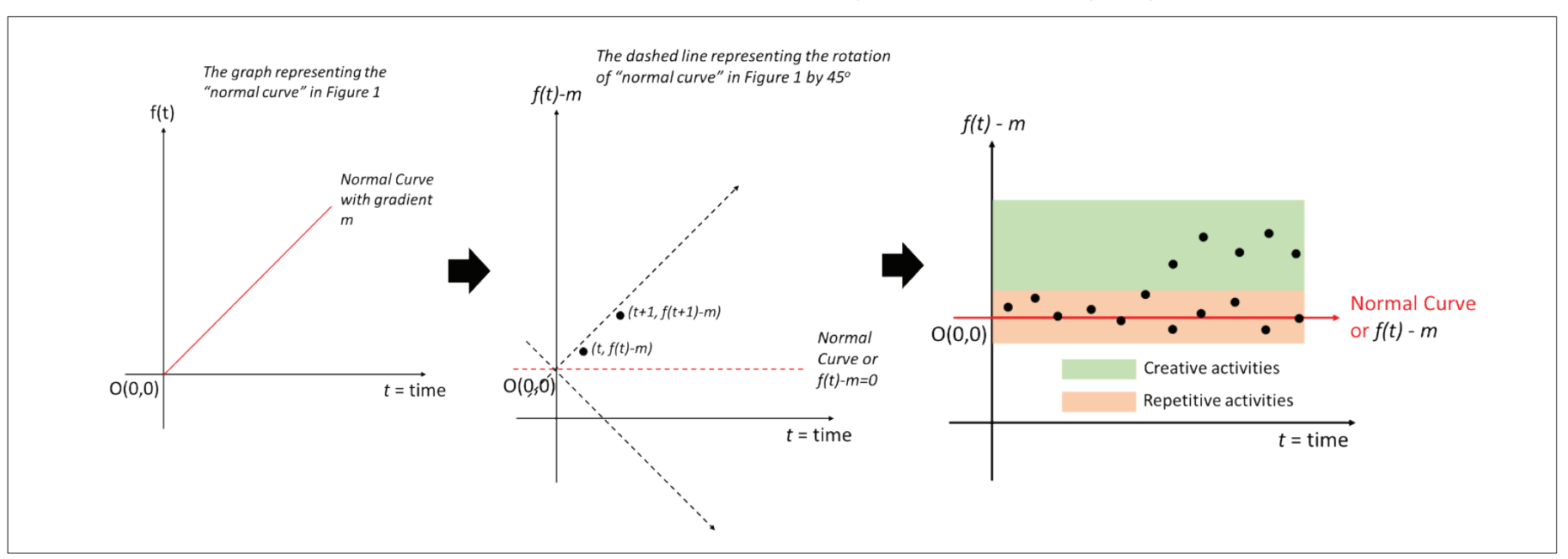


In Figure 3, the "normal curve" of $f(t)-m=0$ indicates the average progress while the black points are the activities with the progress parallel to the "normal curve". By this transformation, the points close to the "normal curve" indicate that the progress is not far from the average progress. Therefore, from this concept, it can be referred that the key to accelerating the progress is to manage the activities such that it makes higher progress than the average progression every year. By the terms of activities management in university, it is equivalent to create creative activities with IAPs such that the IMP would be achieved as soon as possible, or as close as possible to IMP.

In Indonesia's national universities, in order to improve their quality, there is a cost or budget given by the government every year to manage their activities. If the activities are not finished in one year, the cost of the unfinished activities should be sent back to the government. Based on this case, there are two constraints in the activities management of the university, those are cost and time (Sanchez et al, 2017).

Management of activities based on the constraint of cost. The result of this study is a description of how to accelerate the progression of KPI completion by creating a "creative curve" that has a higher gradient than the "normal curve" and its interpretation to the management of activities in a university. The interpretations are made by observation of the activities' management in one of the national universities in Indonesia through the IMP and IAP. Simulations are used to describe the importance of creativity in the constraints of time and cost separately, then compared to the data received by the observation.

Table 1: The simulation for creating the optimal IAPs based on the constraint of cost

\begin{tabular}{cccc}
\hline Number of faculties & IAP & Cost/ faculty & Effect to IMP \\
\hline$x_{1}$ & Training & $\$ 730$ & Indirectly $(0.1 \%)$ \\
\hline$x_{2}$ & Fund research & $\$ 3650$ & Indirectly $(0.2 \%)$ \\
\hline$x_{3}$ & Conference & $\$ 1460$ & Indirectly $(0.4 \%)$ \\
\hline$x_{4}$ & Fund PhD / doctoral study & $\$ 36500$ & Directly $(100 \%)$ \\
\hline
\end{tabular}

The simulation in Table 1 is used to describe the management of activities with the constraint of cost. The IMP " $80 \%$ faculties with Ph.D." would be attained by the IAP presented in Table 1. Every year, the university should find the optimum value for IAP within the limited budget. The simulation aims to find the optimal value of $x_{1}, x_{2}, x_{3}$ and $x_{4}$ such that the maximum progress will be attained with the maximum cost of $\$ 73000$. Thus the model for this simulation is as Eqs. 2.

Maximizing the $f\left(x_{1}, x_{2}, x_{3}, x_{4}\right)=\frac{x_{1} c_{1}}{100}+\frac{x_{2} c_{2}}{50}+\frac{x_{3} c_{3}}{25}+x_{4} c_{4}$

1. $x_{1} c_{1}+x_{2} c_{2}+x_{3} c_{3}+x_{4} c_{4} \leq \$ 73000$,

2. $x_{1}, x_{2}, x_{3}, x_{4} \geq 0$,

In which $c_{1}, c_{2}, c_{3}$ and $c_{4}$ are the corresponding cost to the IAP exposed in Table 1 . By the nonlinear optimization, the optimal value of $\overline{\boldsymbol{x}}$ is $\overline{\boldsymbol{x}}=\left(x_{1}, x_{2}, x_{3}, x_{4}\right)=(0,0,0,2)$, where the values of $x_{1}, x_{2}, x_{3}$ and $x_{4}$ respectively point to the number of faculties corresponding to the IAPs in Table 1 . This result indicates that this year, the university funds the $\mathrm{PhD} /$ doctoral studies of 2 faculties and does not manage any activities about training, research funding, and conference registration. This result is rational only if there is an unlimited source of faculties that is ready to continue $\mathrm{PhD} /$ doctoral degree study, thus choosing the IAP with direct impact on IMP is an obvious answer. In reality, this option means no investment because in order to reach the maximum progress of KPI completion, there is a limited source of faculties that is ready to continue the study. By concerning the investment, the optimal value becomes $\bar{x}=(1,1,2,1)$.
Based on the simulation, it reveals that the completion progress is directly proportional to the constraint of cost. If the value of available cost is increased, then the obtained value of $f(\bar{x})$ is automatically increased (decreasing the distance between IAP and IMP). Therefore, the result obtained by the simulation does not exhibit the creativity in creating IAPs. This is because it drives the university to conclude that the only way to maximize $f(\overline{\boldsymbol{x}})$ is by finding the value of $(\overline{\boldsymbol{x}})$ with the constant value of cost, so that the progression is constant every year if the result is repetitively used.

The results of the simulation in Table 1 can be further analogous to the horizontal distance $(d)$ of parabolic motion with different initial velocities $\left(v_{o}\right)$ and same degree of elevation $(\alpha)$ in Figure $4 \mathrm{a}$. Figure $4 \mathrm{a}$ demonstrates the correlation of the KPI completion and the constraint of cost as the graph of parabolic motion. In parabolic motion, the formula used to determine the horizontal range or the distance $(d)$ is as Eqs. 3. In this motion, $\left(v_{o}\right)$ denotes as the cost/ budget, $\alpha$ depicts as the management of activities and $d_{n}$ represents the $f(\overline{\boldsymbol{x}})$ or the progression distance of the IAPs while $g$ is a constant. Eqs. 3 reveals that the $d$ is proportional to the $\left(v_{o}\right)$ and $\alpha$. If $\alpha$ is set to be constant/ same, thus if $v_{o_{n}}>v_{o_{n-1}}, n=1,2, \ldots$, then $d_{n}>d_{n-1}$. Hence, $d_{n}$ is mainly affected by the initial velocity of $v_{o_{n}}$. Therefore, according to Figure $4 \mathrm{a}$, since the constraint of cost is analogous to the initial velocity in the graph of parabolic motion, the big progression is reached by the high available budget.

$$
d=\frac{v_{o}^{2} \sin 2 \alpha}{g}
$$


Figure 4: (a) An analogy of parabolic motion to the KPI progression, the constraint of cost is directly proportional to the completion (b) An analogy of parabolic motion to the KPI progression, the maximum progression would be accomplished by adjusting the degree of elevation within the same initial velocity.

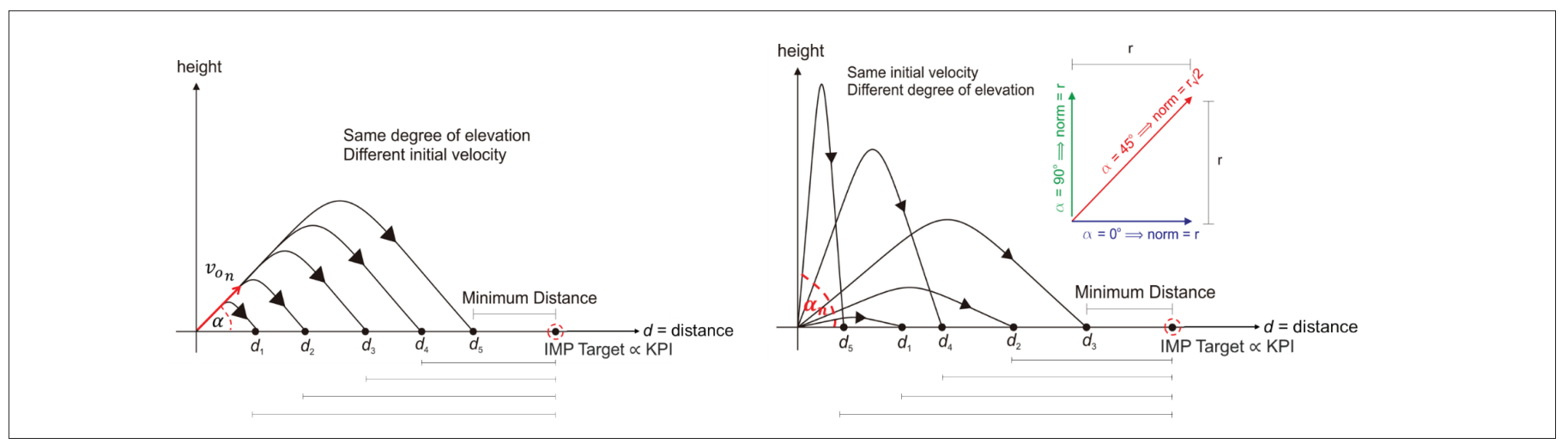

There is an alternative way to maximize the IAPs progression distance $(d)$ or minimize the distance between the IMP and IAP without increasing the constraint of cost. The way is by adjusting the degree of elevation $\alpha$ as in Figure 4b. In parabolic motion, the degree of elevation also affects the acceleration of the moving object. If the initial velocity is constant/ same, now the distance is only dependent on the degree of elevation. In addition to the maximum norm of a vector, the elevation degree $\alpha$ of $45^{\circ}$ will produce a maximum value of $2 \alpha$ based on Eqs. 3, thus the maximum distance progression can be attained by this degree. This graph indicates that the higher progression of IAPs could be achieved by management of activities properly.

To further discuss, there is a quantitative measurement for creativity (Usta \& Akkanat, 2015) defined by the level of creativity ( $L O C$ ). Figure 5 shows the $L O C$ based on the numbers of IAPs and IMPs. The degree of elevation $(\alpha)$ denotes the $L o C$. In this case, the maximum progress of KPI completion would be achieved by reducing the cost stated in Table 1 to its corresponding IAPs. Let $L O C$ be a fuzzy variable in the interval of $[0,1]$.To synchronize the properties of $L o C$ and the degree of elevation $(\alpha)$ in Figure $4 \mathrm{~b}$, the maximum value of $L o C$ indicates the maximum norm of activity vector $\bar{v}=\left(n_{I A P}, n_{I M P}\right)$, where $n_{I A P}$ and $n_{I M P}$ are respectively the numbers of IAPs and IMPs which would be accomplished by activities.

Figure 5: Illustration of $L o C$ based on the numbers of IAPs and IMPs. The highest $L O C$ occurred when the corresponding activity can gain many IAPs and IMPs at once ( $L O C=1$ or $\alpha=45^{\circ}$ ). The lowest $L O C$ occurred when the corresponding activity only obtains single IAP and single IMP ( $L o C=0$ or $\alpha=0^{\circ}$ or $\mathrm{r} \alpha=90^{\circ}$ ). The conversion of $[0,1]$ to the elevation degree can be simplified to $\left[0^{\circ}, 45^{\circ}\right]$.

\begin{tabular}{|l|c|c|c|}
\hline & $\begin{array}{l}\text { Medium LoC } \\
\text { Fedium cost }\end{array}$ & $\begin{array}{l}\text { High LoC } \\
\text { Low cost }\end{array}$ & $\begin{array}{c}\text { High LoC } \\
\text { Low cost }\end{array}$ \\
FEW & $\begin{array}{l}\text { Low LoC } \\
\text { High cost }\end{array}$ & $\begin{array}{l}\text { Medium LoC } \\
\text { Medium cost }\end{array}$ & $\begin{array}{c}\text { High LoC } \\
\text { Low cost }\end{array}$ \\
SINGLE & $\begin{array}{c}\text { Low LoC } \\
\text { High cost }\end{array}$ & $\begin{array}{l}\text { Low LoC } \\
\text { High cost }\end{array}$ & $\begin{array}{c}\text { Medium LoC } \\
\text { Medium cost }\end{array}$ \\
& SINGLE & FEW & MANY \\
\hline
\end{tabular}

According to Figure 5, $L O C$ is inversely proportional to the cost of activities. An activity with high $L o C$ gains many IAPs, thus by paying/ funding the cost of an activity, many IAPs would be obtained at once. This method generates a shorter distance between IAP and IMP by allocating the remaining cost to the other activities. This kind of activity is defined as a creative activity.

Let an activity possesses a single $n_{I A P}$ and many $n_{I M P}$ and many, thus the $L O C$ of this activity is included to medium $\operatorname{LoC}$ by Figure 6 . The obtained result of $f(\overline{\boldsymbol{x}})$ by this activity management is higher than the simulation in Table 1 within the same constraint of cost. In Table 1, every activity has low $L O C$ (single $n_{I A P}$ and single $n_{I M P}$ ).

An example is given to explain this implication. If the activities of "fund research" in Table 1 are also used in the IMP of " 6 new publications per faculties" and IMP of " 15 new books per faculties", thus the cost associated with these activities is distributed to three IMPs at once. This reduces the value of $C_{2}$ in Table 1 and the obtained result of $f(\overline{\boldsymbol{x}})$ is increased within the same constraint of cost.

Management of activities based on the constraint of time. KPIs are derived into quantitative information (IMPs) as the measurable indicators of its completion. IAPs are the outputs of activities managed by the university. Activities are managed in sequence to create progress in KPI completion. By holding the activities in sequence, the IAP of the first activity can be initiated for the next activity. An example of this idea is presented in Table 1. The activities of "fund research" should be held before the "conference" thus the progression elevates from $0.2 \%$ to $0.4 \%$ in the same year. The cost of the unfinished activities of a national university is sent back to the government at the end of the year, thus a university has to finish every activity with the constraint of time (1 year).

Observation is conducted to find the pattern of distributed activities in a year managed by one of the national universities in Indonesia. The obtained data of this observation is demonstrated in Figure 6. It resembles the exponential function. Figure 6 depicts that the number of activities held in December is more than half of the total activities. Compared to the first month, it is more than $5000 \%$ of the number of activities held in January. Most of the IAP will be finished next year by 
this management. Increasing the constraint of time is impossible because it is the regulation from the government (Kementrian Riset Teknologi dan Perguruan Tinggi, 2016). If this management is repeated, then the completion progress is constant. By Figure 2, acceleration does not occur when the progress is constant every year.

Figure 6: The plot of activities managed by the university to the months in a year. This plot does not reflect effective management because most of the activities were held in December.

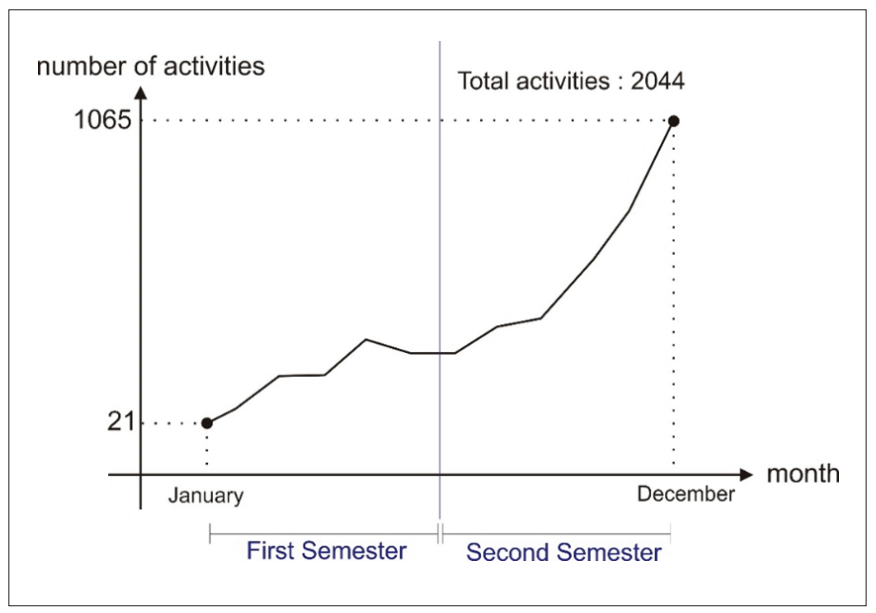

Obviously, if most of the activities are held in the last month of the year, there is not any additional duration that suffices these activities to accomplish more IAPs. Acceleration occurs when activities are initiated as soon as possible in the first semester. On the other hand, it is unwise to put all the activities in the first month[18] because high LoC activities are possible to be designed by managing them to be held on the right month. It is necessary to understand how to manage the activities such that they have high $L o C$ according to the month when those activities are held.

The academic phase is then used to simplify the process of designing activities with high $L o C$. The academic phase contains phases of student progression in completing their study. The academic phase of the undergraduate students (within 4 years) is illustrated in Figure 7. In Figure 7, the activities should be scheduled by synchronizing the IAP with the phases. For example, the activities with IMP to generate the mutual relationship with the business industries (excluding university, institute, or academy) should be scheduled during the internship and practical phase, thus the students are participated to gain the IMP.

Figure 7: The academic phases of undergraduate study in Indonesia. There are 4 phases in the academic phase of the undergraduate students; those are orientation, classroom study, internship and practical study, and final assessment before graduating. The red curve points to academic activities and the green curve represents career development.

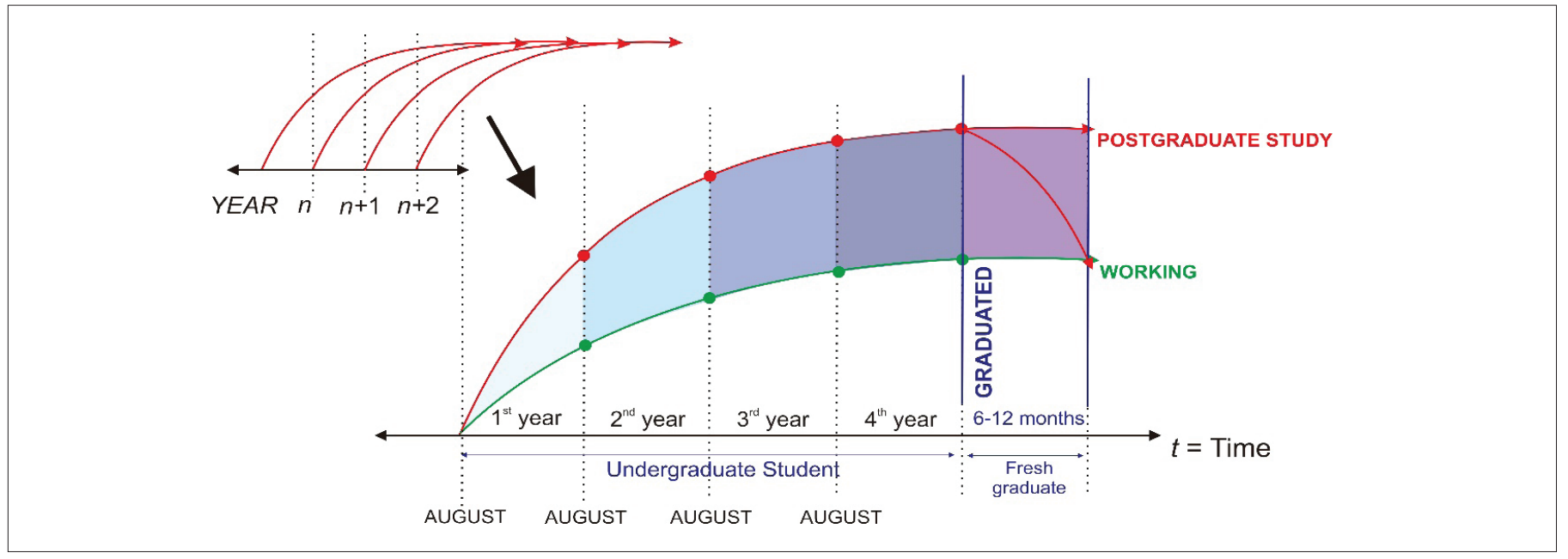

The idea of synchronizing the schedule of these activities and the academic phases of students forms a mutual relation between the university and the students. The internship in the business industry gives working experience to the student. The students have to assist in forming a research paper supervised by the faculties and publish it. The IAPs of these activities (internship and research) accomplish 3 IMPs at once ("100 mutual relation with business industry", "50 research collaboration with industry" and "6 new publications per faculty"), thus it has high $\mathrm{LoC}$.

It is clarified that activity with high $\operatorname{LoC}$ causes acceleration in completing KPI, thus the key to manage activities with the constraint of time is to design as many activities with high $L O C$ as possible within the time constraint. A schedule of designed activities is made and acceleration occurs when the activities are finished on time, thus a discipline to follow the schedule is necessary. University has to build an organizational culture to manage the activities on schedule (Lapina et al, 2015).

\section{Conclusions}

Creative University is defined by a university with creative activities such that the KPIs can be finished in less duration and budget. The remaining time and cost then can be exploited to continuously 
improve its quality. There are three ways to accelerate the completion of KPI towards a creative university, those are creating activities that could minimize the distance between IAP and IMP, managing the schedule of activities, and realizing it based on the strategy of academic phases in a university. The creativity of activities is measured by LoC Activities with high $L O C$ create acceleration to complete the KPI of a university.

\section{Acknowledgment}

The authors would like to thank Universitas Sebelas Maret (UNS) which has for 4 years made a university planning system towards a world class university.

\section{Conflict of Interest}

The author declares that there is no conflict of interest in this study.

\section{References}

AlRababah, A. A. Q. (2017). A New Model of Information Systems Efficiency based on Key Performance Indicator (KPI). (IJACSA) International Journal of Advanced Computer Science and Applications, 8(3), 81-83. DOI: 10.14569/IJACSA.2017.080313

Aurora, A., \& Kaur, S. (2015). Performance Assessment Model for Management Educators Based on KRA/KPI. International Conference on Technology and Business Management, 218-221.

Badawy, M., El-Aziz, A. A. A., Idress, A. M., Hefny, H., \& Hossam, S. (2016). A survey on exploring key performance indicators. Future Computing and Informatics Journal, 1, 47-52. http://dx.doi. org/10.1016/j.fcij.2016.04.001

Bartle, R. G., \& Sherbert, D. R. (2011). Introduction to Real Analysis, 4th Edition ed., John Wiley \& Sons, Inc.

Brockunier, E. D. (2016). An Investigation of Creativity, Engagement, and Academic Success Using Student-Led Lesson Planning in One Third Grade Classroom. Curriculum and Instruction Undergraduate Honors Theses, 13.

Europian Commission. (2013). Measuring innovation output in Europe: towards a new indicator. SWD, 35.

Hu, W., \& Adey, P. (2002). A scientific creativity test for secondary school students. International Journal of Science Education, 24(4) 389-403. http://dx.doi.org/10.1080/09500690110098912

Janger, J., Schubert, T., Andries, P., Rammer, C., \& Hoskens, M. (2017). The EU 2020 innovation indicator: A step forward in measuring innovation outputs and outcomes?. Research Policy, 46(1), 30-42.

Kementrian Riset Teknologi dan Perguruan Tinggi. (2016). Peraturan Menteri Riset, Teknologi dan Perguruan Tinggi tentang Pedoman Penyusunan Laporan Kinerja Perguruan Tinggi Beradan Hukum. Kemenristekdikti. https://peraturan.bpk.go.id/Home/Download/132668/ Permenristekdikti\%20Nomor\%2040\%20Tahun\%202016.pdf
Lapiņa, I., Kairiša, I., Aramina, D. (2015). Role of Organizational Culture in the Quality Management of University. Procedia - Social and Behavioral Sciences, 213, 770-774. doi: 10.1016/j.sbspro.2015.11.472

Louca, E. P., Marouchou, D. V., Mihai, S., Konis, E. (2014). Teaching for Creativity in Universities. Journal of Education and Human Development, 3(4), 131-154. http://dx.doi.org/10.15640/jehd.v3n4a13

Lund, B., \& Arndt, S. (2018). The Creative University. Brill, Leiden.

Martini, L. (2016). Knowledge Sharing in a Creative City. Procedia Computer Science, 99, 79-90. doi: 10.1016/j.procs.2016.09.102

Parkinson, C. N. (1957). Parkinson's Law: and other Studies in Administration. The Riverside Press, Massachusetts, USA.

Parkinson, C. N. (1958). Parkinson's Law: or, The pursuit of progress. J. Murray, London.

Peter, K. A. (2014). Appraising Effectiveness of Key Performance Indicators used by Nigerian Construction Firms. International Journal of Education and Research, 2(12), 451-460.

Prayudi, Probosari, N., \& Ardhanariswari, K. A. (2017). Analysis of the Development of Bandung as Creative City. International Journal of Scientific \& Engineering Research, 8(9), 1025-1030.

Ritter, S. M., Gu, X., Crijns, M., \& Biekens, P. (2020). Fostering students' creative thinking skills by means of a one-year creativity training program. PLoS ONE, 15(3), e0229773. https://doi.org/ 10.1371/ journal.pone.0229773

Sanchez, O. P., Terlizzi, M. A., \& Moraes, H.R.d.O.C. (2017). Cost and time project management success factors for information systems development projects. International Journal of Project Management, 35(8), 1608-1626. https://doi.org/10.1016/j.ijproman.2017.09.007

Sawang, S. (2011). Key Performance Indicators for Innovation Implementation: Perception vs. Actual Usage. Asia Pacific Management Review, 16(1), 23-29. DOI:10.6126/APMR.2011.16.1.02

Secundo, G., Perez, S. E., Martinaitis, Ž., Leitner, K.H. (2017). An Intellectual Capital framework to measure universities' third mission activities. Technological Forecasting and Social Change, 123, 229239. http://dx.doi.org/10.1016/j.techfore.2016.12.013

Selviyanti, E., Sardjono, W., Mukhlis, M., Tohir, M., Maswar, M., \& Fariz, A. (2021). Model of developing key performance indicator to increase the quality of education during the Covid-19 pandemic. Journal of Physics: Conference Series, 1832, 012030. doi:10.1088/1742$6596 / 1832 / 1 / 012030$

Şen, A., Kabak, K. E., Tüysüz, F., \& Kuzaliç, D. (2012). Democratization of University Management for Quality Higher Education. Procedia - Social and Behavioral Sciences, 58, 1491-1504. doi: 10.1016/j. sbspro.2012.09.1136S 
Suyidno, E. S., Arifuddin, M., Misbah, Sunarti, T., \& Dwikoranto. (2019). Increasing Students' Responsibility and Scientific Creativity through Creative Responsibility Based Learning. Jurnal Penelitian Fisika dan Aplikasinya (JPFA), 9(2), 178-188. DOI: 10.26740/jpfa.v9n2. p178-188
Usta, E., \& Akkanat, Ç. (2015). Investigating Scientific Creativity Level of Seventh Grade Students. Procedia - Social and Behavioral Sciences, 191, 1408-1415. doi: 10.1016/j.sbspro.2015.04.643

Villazón, C. C., Pinilla, L. S., Olaso, J. R. O., Gandarias, N. T., \& Lacalle, N. L. (2020). Identification of Key Performance Indicators in Project-Based Organisations through the Lean Approach. Sustainability, 12(15), 5977. doi:10.3390/su12155977 